\title{
Sukusiitos suomalaisessa sinikettupopulaatiossa
}

Ismo Strandén ja Jussi Peura

MTT - Kotieläintuotannon tutkimus, 31600 Jokioinen, etunimi.sukunimi@mtt.fi

\section{Tiivistelmä}

Eläinjalostuksella valitaan usein perimältään läheisiä tai melko läheisiä sukulaisia ja onkin tunnettua että jalostusvalinta nostaa sukusiitosastetta. Tyypillisesti sukusiitoksen kasvu heikentää eläinten hedelmällisyyttä ja terveyttä sekä rakenteeseen ja kestävyyteen liittyviä ominaisuuksia. On arvioitu että $10 \%$ sukusiitos heikentää keskimäärin noin puoli pentua siniketun pentuekokoa. Siniketun koko on kasvanut runsaat kymmenen vuotta huomattavasti ja samalla huoli muista ominaisuuksista, kuten hedelmällisyydestä ja rakenteesta, on kasvanut. Tässä tutkimuksessa tarkastelimme sukusiitoksen ja sukulaisuusasteen muutosta sekä arvioimme efektiivisen populaatiokoon Suomen sinikettupopulaatiolle.

Vuonna 2001 syntyneiden sukusiitos oli keskimäärin 1\% tarkastellussa sinikettupopulaatiossa. Sukusiitos oli alhaisempi siitokseen käytettyjen yksilöiden joukossa kuin koko populaatiossa. Tämä voi johtua mm. tahallisesta sukusiitoksesta joidenkin värityyppien saamiseksi, ja sukusiitosta estävän paritusohjeistuksen toimivuudesta. Sukusiitos nousi melko alhaisella vauhdilla: 0,06\% vuodessa. Sukusiitosaste näyttäisi kehittyneen vuoden 1997 jälkeen noin kaksinkertaisella vauhdilla eli 0,13\% vuodessa. Tämä arvio on epävarma, koska tarkasteltu aineisto loppuu vuoteen 2002.

Sukulaisuusaste oli muuttumaton vuodesta 1990 vuoteen 1997, jonka jälkeen se alkoi kohota. Vuonna 1998 syntyneitä siitoseläimiä on huomattavasti vähemmän kuin vuodelta 1997. Tämä johtuu turkistuotannon markkinahintojen romahduksesta, jonka seurauksena turkistuotantoa vähennettiin huomattavasti. Vuonna 1998 syntyneitä siitosuroksia oli noin kolmannes vähemmän kuin edellisenä vuonna Suomen sinikettupopulaatiossa. Siitoksessa käytettävien sinikettu-urosten määrä on vasta viime vuosina palautunut aikaisemmalle tasolle.

Keskimääräinen sukupolvenväli oli noin 1,87 vuotta. Kun sukusiitoksen nousuvauhtina pidetään $0,06 \%$ vuodessa, efektiiviseksi populaatiokooksi saadaan 423. Kun nousuvauhti on $0,13 \%$, niin efektiivinen populaatiokoko on 199. Molemmat luvut ovat kohtalaisen suuria kun niitä verrataan tyypillisiin jalostuspopulaatioihin. Esimerkiksi monien lypsykarjarotujen efektiivinen populaatiokoko on alle 100.

Sinikettupopulaation sukusiitoksen määrään vaikuttaa erityisesti siitosurosten määrä, johon vaikuttavat turkisten maailmanmarkkinahinnat. Vaikka nykyinen sukusiitoksen taso ja nousuvauhti eivät ole huolestuttavia, niin äkilliset siitosurosten määrien heilahtelut voivat aiheuttaa ns. pullokaulailmiön, jolloin geneettinen vaihtelu pienenee. Sukusiitosaste voi lisääntyä myös aiempaa harvempien urosten siitoskäytöllä, johon keinosiemennys antaa mahdollisuuden. Tällä hetkellä sukusiitoksesta voitaneen havaita ongelmia vain joillain tiloilla, mutta ei yleisesti Suomen sinikettupopulaatiossa.

Asiasanat: eläinjalostus, populaatiokoko, sinikettu, sukulaisuusaste, sukusiitos 


\section{Johdanto}

Eläinjalostuksen pyrkimyksenä on muuttaa haluttuja ominaisuuksia populaatiossa. Tunnetusti tehokas eläinjalostusohjelma aiheuttaa sukusiitosasteen nousua, sillä ovathan parhaat geenit usein samoissa perheissä. Tyypillisesti sukusiitoksen kasvu heikentää eläinten hedelmällisyyttä ja terveyttä sekä rakenteeseen ja kestävyyteen liittyviä ominaisuuksia. On arvioitu että $10 \%$ sukusiitos heikentää keskimäärin noin puoli pentua siniketun pentuekokoa (Nordrum 1994, Wierzbinski ym. 2004).

Tässä tutkimuksessa tarkastelimme keskimääräisen sukusiitosastetta ja sukulaisuusastetta Suomen sinikettupopulaatiossa. Arvioimme myös efektiivisenpopulaatiokoon.

\section{Aineisto ja menetelmät}

\section{Aineisto}

Sukupuu on Sampo rekisteristä, joka on kerätty tiloilta Suomen Turkistuottajien Liiton (STKL) toimesta. Sukupuusta lasketut tilastot ovat valituilta 138 tilalta. Näillä tiloilla oli vähintään 50 kettua vuosittain 5 perättäisenä vuotena aikana 1993-2002. Sukupuussa oli noin 2,5 miljoonaa eläintä. Valituilla tiloilla oli näistä suurin osa eli noin 1,94 miljoonaa sinikettua (Taulukko 1).

Taulukko 1. Tilojen määrä ( $\left.\mathrm{N}_{\text {Tila }}\right)$, tiloilla olevien eläinten mediaani määrä $(\mathrm{M})$, sekä siitokseen käytettyjen urosten $\left(\mathrm{N}_{\mathrm{M}}\right)$ ja naaraiden $\left(\mathrm{N}_{\mathrm{F}}\right)$ kokonaismäärät syntymävuosittain.

\begin{tabular}{|c|c|c|c|c|c|c|}
\hline \multirow[b]{2}{*}{ Vuosi } & \multicolumn{2}{|c|}{ Kaikki eläimet } & \multicolumn{4}{|c|}{ Siitoseläimet } \\
\hline & $\mathrm{N}_{\text {Tila }}$ & $\mathrm{M}$ & $\mathrm{N}_{\text {Tila }}$ & $\mathrm{M}$ & $\mathrm{N}_{\mathrm{M}}$ & $\mathrm{N}_{\mathrm{F}}$ \\
\hline 1990 & 66 & 37 & 66 & 30 & 289 & 1867 \\
\hline 1991 & 85 & 84 & 85 & 43 & 521 & 4228 \\
\hline 1992 & 100 & 120 & 100 & 49 & 694 & 5520 \\
\hline 1993 & 110 & 178 & 110 & 66 & 1062 & 7659 \\
\hline 1994 & 121 & 358 & 121 & 66 & 1293 & 9434 \\
\hline 1995 & 128 & 589 & 128 & 86 & 1710 & 12314 \\
\hline 1996 & 136 & 1001 & 136 & 96 & 1955 & 19583 \\
\hline 1997 & 138 & 1099 & 134 & 99 & 2064 & 14426 \\
\hline 1998 & 134 & 1344 & 131 & 62 & 1614 & 9244 \\
\hline 1999 & 130 & 1012 & 129 & 105 & 1917 & 15868 \\
\hline 2000 & 128 & 1427 & 128 & 106 & 2055 & 15537 \\
\hline 2001 & 128 & 1672 & 126 & 87 & 2089 & 12166 \\
\hline 2002 & 125 & 1603 & - & - & - & - \\
\hline
\end{tabular}

\section{Sukulaisuuden mitat ja efektiivinen populaatiokoko}

Kullekin syntymävuodelle laskettiin kaksi sukulaisuusmittaa: sukulaisuusaste ja sukusiitosaste. Vuosittainen keskiarvo näistä mitoista laskettiin tilojen keskiarvoista, koska sinikettujen jalostus on pääosin tilan sisäistä. Eläimen $i$ sukusiitosaste on $F_{i}=\frac{1}{2} a_{s d}$ jossa $a_{s d}$ on sukulaisuusmatriisin elementti eli sukulaisuusaste eläimen isän ja emän välillä. Sukulaisuusaste laskettiin kaikkien samana vuonna syntyneiden tilan eläinten välille, sekä erikseen vielä vain siitokseen käytettyjen eläinten välillä.

Efektiivinen populaatiokoko on $N_{e}=1 /(2 \Delta F)$ jossa sukusiitosasteen nousuvauhti sukupolvessa on $\Delta F=\left(F_{t}-F_{t-1}\right) /\left(1-F_{t-1}\right)$, kun $F_{t}$ on keskimääräinen sukusiitosaste sukupolvella $t$. Sukusiitosasteen nousuvauhti voidaan kirjoittaa myös muodossa $\Delta F=l b /\left(1-F_{\text {last }}+l b\right)$ (Gutierrez ym. 2003) jossa $l$ on keskimääräinen sukupolven väli, $b$ on keskimääräinen sukusiitoksen nousuvauhti syntymävuoden mukaan laskettuna, and $F_{\text {last }}$ on keskimääräinen sukusiitosaste viimeisenä tarkasteltuna vuotena.

\section{Tulokset ja tulosten tarkastelu} Sukusiitos ja sukulaisuusaste

Sukusiitosaste nousi syntymävuoden mukaan sekä siitokseen käytettyjen että kaikkien eläinten ryhmässä 
(Kuvio 1). Siitokseen käytettyjen yksilöiden keskimääräinen sukusiitosaste oli kuitenkin alhaisempi kuin kaikilla eläimillä. Sukusiitosasteen erilaisuus voi johtua tarkoituksellisesta sukusiitoksesta halutun turkislaadun tuottamiseksi tai sukusiitoksen välttämisestä siitoseläimillä.

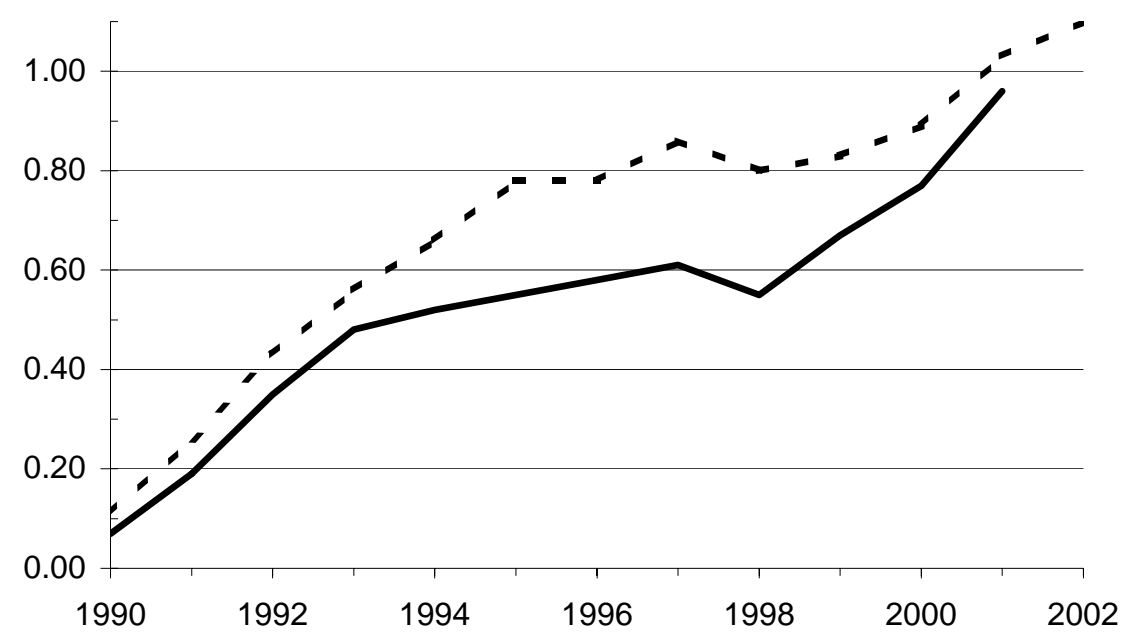

Kuvio 1. Keskimääräinen sukusiitos prosentteina syntymävuoden mukaan siitoseläimille (yhtenäinen viiva), ja kaikille eläimille (katkoviiva).

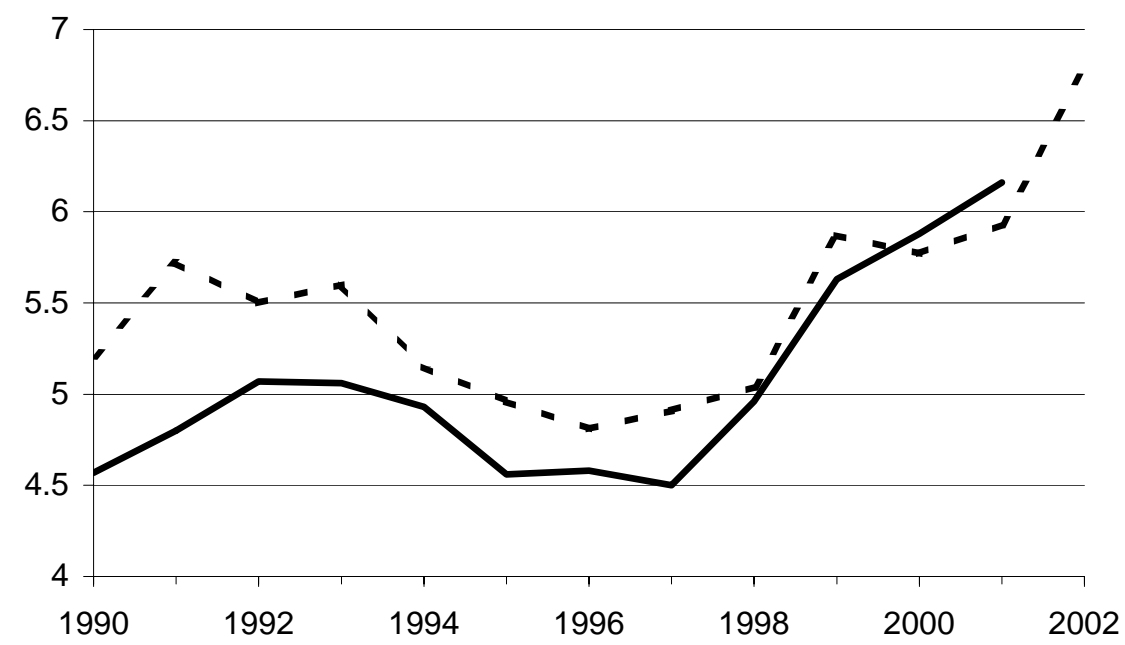

Kuvio 2. Keskimääräinen sukualaisuusaste prosentteina syntymävuoden mukaan siitoseläimille (yhtenäinen viiva), ja kaikille eläimille (katkoviiva).

Keskimääräinen sukulaisuusaste tiloilla siitoseläimillä ja kaikilla eläimillä oli lähes muuttumaton vuodesta 1990 vuoteen 1997 (Kuvio 2). Vuosina 1998 ja 1999 sukulaisuusaste alkoi nousta huomattavasti. Vastaavasti siitoseläinten määrä laski vuodesta 1997 vuoteen 1998 (Taulukko 1). Vuonna 1997 turkisnahkojen hinnat laskivat huomattavasti, ja turkistuotannon määrä vähennettiin. Toinen seuraus on aikaisempaa hivenen nopeampi sukusiitosasteen nousuvauhti vuoden 1998 jälkeen (Kuvio 1). 


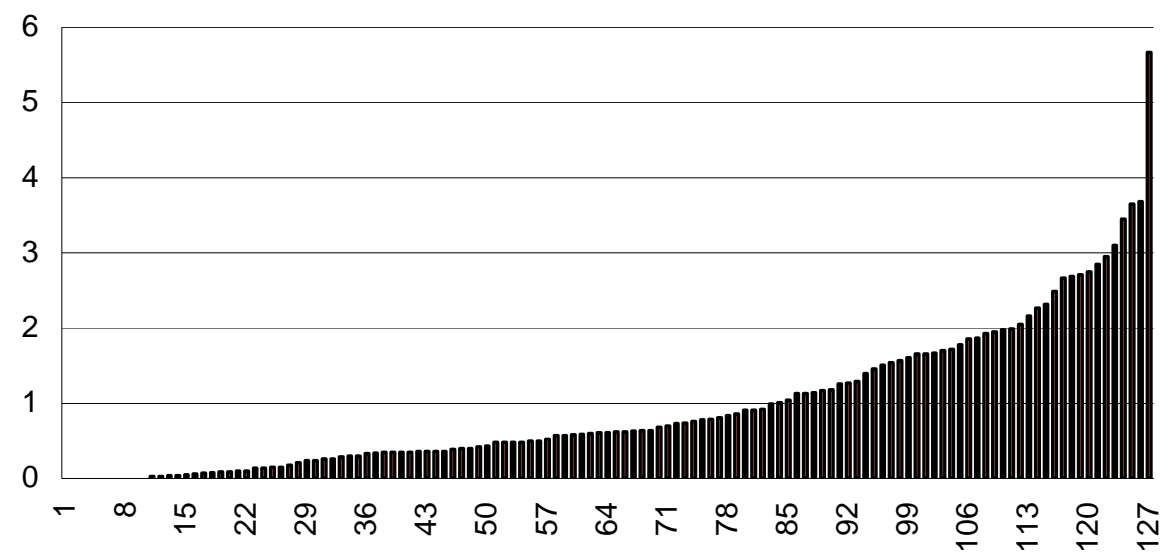

Kuvio 3. Keskimääräinen sukusiitosasteen prosentti tiloilla vuonna 2001 syntyneillä siitoseläimillä.

Sukusiitos ei näyttäisi olevan merkittävä ongelma suurimmalla osalla valittuja tiloja: noin $66 \%$ tiloista sukusiitos oli keskimäärin alle 1\% (Kuvio 3). Viidellä tilalla keskimääräinen sukusiitos oli yli 3\%. Kutsutaan näitä tiloja kirjaimilla A:sta E:ään. Tiloilla A, B, C, D ja E keskimääräinen sukusiitosaste oli 5,67\%, 3,68\%, 3,65\%, 3,45\%, and 3,10\%. Niiden eläinten osuus, joilla sukusiitos oli yli 5\% oli 51,1\%, 26,3\%, 21,0\%, 31,4\%, and 13,0\% tiloilla A:sta E:hen.

\section{Efektiivinen populaatiokoko}

Keskimääräinen sukupolvenväli arvioitiin aineistossa olevan 1,87 vuotta vuosina 1994-2001 syntyneille eläimille. Keskimääräinen sukusiitoksen nousu vuosina 1990-2001 syntyneillä siitoseläimillä oli 0,0626\% per vuosi (Kuvio 1). Näiden lukujen perusteella, efektiivisen populaatiokoko arvioitiin olevan 423.

Sukusiitoksen nousuvauhti on kiihtynyt viime vuosina (Kuvio 1) mutta sukupolven välissä emme havainneet merkittävää muutosta. Keskimääräinen sukusiitoksen nousu vuosina 1998-2001 syntyneillä arvioitiin olevan 0,133\% vuodessa. Tätä lukua käyttämällä efektiiviseksi populaatiokooksi saadaan 199. Vaikka tämä on huomattavasti pienempi kuin em. 423, niin jalostuspopulaatiolle se ei ole liian alhainen. Mainittakoon, että lypsykarjapopulaatioiden efektiivinen populaatiokoko on tyypillisesti alle 100. Sinikettupopulaation sukusiitoksen määrään vaikuttaa ratkaisevasti siitosurosten määrä, johon vaikuttavat turkisten maailmanmarkkinahinnat. Markkinoiden paineessa onkin erityisesti huolehdittava riittävistä siitoseläinmääristä. Sukusiitosaste voi lisääntyä myös aiempaa harvempien urosten siitoskäytöllä, johon keinosiemennys antaa mahdollisuuden.

\section{Johtopäätökset}

Sukusiitos ei näyttäisi olevan merkittävä ongelma Suomen sinikettupopulaatiossa, koska sukusiitoksen nousuvauhti ja sen taso ovat alhaisia. Tämän seurauksena efektiivinen populaatiokoko on riittävän korkea. Nykyiset käytännöt sukusiitoksen estämiseksi tuntuvat riittäviltä ja toimivan hyvin. On kuitenkin mahdollista että joillain tiloilla sukusiitos on liian korkealla tasolla ja myös sukusiitoksesta johtuvat ongelmat ovat havaittavissa.

\section{Kirjallisuus}

Gutiérrez, J.P., Altarriba, J., Díaz, C., Quintanilla, R., Cañón, J. \& Piedrafita, J. 2003. Pedigree analysis of eight Spanish beef cattle breeds. Genet. Sel. Evol. 35: 43-63.

Nordrum, N.M.V. 1994. Effect of inbreeding on reproductive performance in blue fox (Alopex lagopus) Vixens. Acta Agric. Scand. Sec. A, 44: 214-221.

Wierzbicki, H., Peura, J., Zuk, B. \& Strandén, I. 2004. A comparison of inbreeding effect on litter size and fur coat traits in Finnish and Polish blue fox populations. Animal Science Papers and Reports. 22 (suppl. 2): 165-170. 